\title{
COPIM•
}

\section{Tentative Florilegium: Experiments \& Recipes for ReWriting Books}

\section{Julien McHardy}

Published on: $\operatorname{Sep} 30,2021$

License: Creative Commons Attribution 4.0 International License (CC-BY 4.0). 
Digital publishing tools and non-restrictive copyright regimes make it possible to incorporate source texts and data in ways that go beyond conventional citation practices, re-assessing the relationships between publications and their sources while providing full attribution. In the summer of 2021, COPIM's Experimental Publishing Group hosted

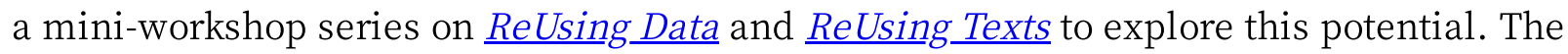
ReUsing Data workshop experimented with how scholars and new kinds of data books might assemble, relate, expose and perform data differently.

The ReUsing Texts workshop focused on how scholars might gather, engage, (dis)appropriate, remix and rewrite existing texts. The Combinatorial Books: Gathering Flowers project, set up by COPIM, Open Humanities Press and Gabriela Méndez Cota explores rewriting as a way of writing books. We co-hosted the workshop with Gabriela's team of scholars, technologists, and students from the Universidad Iberoamericana Ciudad de México and their work inspired the event. Gabriela and her team set out to collaboratively 'rewrite' Tondeur and Marder' s book The Chernobyl Herbarium: Fragments of an Exploded Consciousness (Open Humanities Press, 2016).

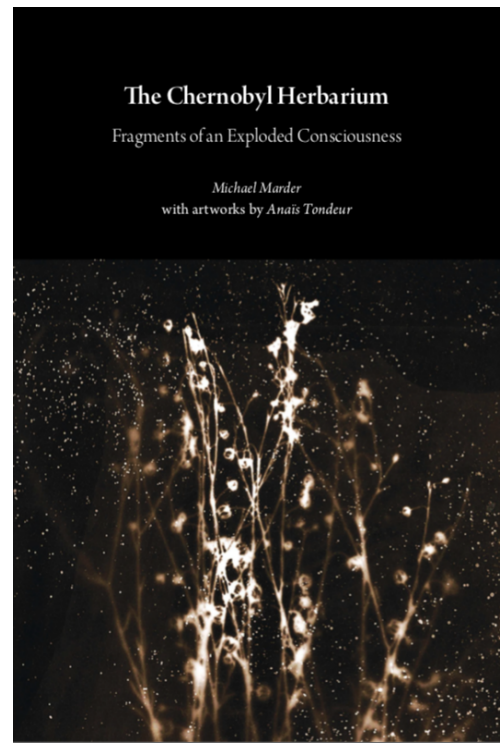

Marder. The Chernobyl Herbarium: Fragments of an Exploded Consciousness (Open Humanities Press, 2016).
Using rewriting as a method, they explore the history of nuclear power and socioenvironmental devastation from the standpoint of particular plants known in Mexico as quelites. They are working towards a book-length response that will be published by Open Humanities Press under the title: Ecological Rewriting as Disappropriation: Situated Engagements with the Chernobyl Herbarium. Drawing on this work, we invited workshop participants to engage with and around fragments of the Chernobyl Herbarium: Collaborating on a video stream and in Cryptpad, they thought about what insights diverse plants' behaviours could offer regarding the rewriting, publishing, composting, and circulating of sources and resources. The plant-inspired procedures were then tested through rewriting a passage from the Chernobyl Herbarium and made available as tentative recipes for rewriting texts. 


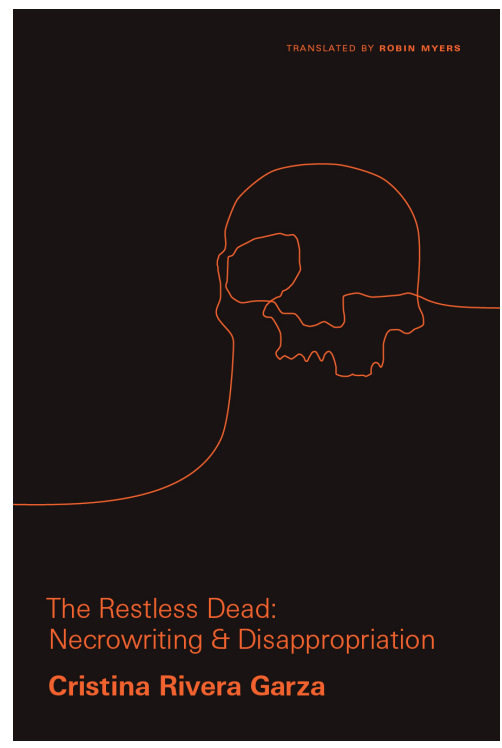

Rivera Garza. The Restless Dead: Necrowriting_and Disappropriation (Vanderbilt UP, 2020).

Books.

The techniques experimented with during the workshop drew on Cristina Rivera Garza' s understanding of rewriting as misappropriation. As Gabriela Mendéz Cota states in a recent blogpost: "Rewriting, Garza says, is not about appropriation, but rather it is about exposing the incomplete, processual nature of any text; it is about making time and taking the time, and it is about relating to others in accountable ways. Beyond Rivera Garza' s formulations, we would like to explore ways of becoming accountable for invisible connections between human and non-human aspects of contemporary devastation, and for the scalar conflicts which any ethical or political narrative inevitably inhabits."

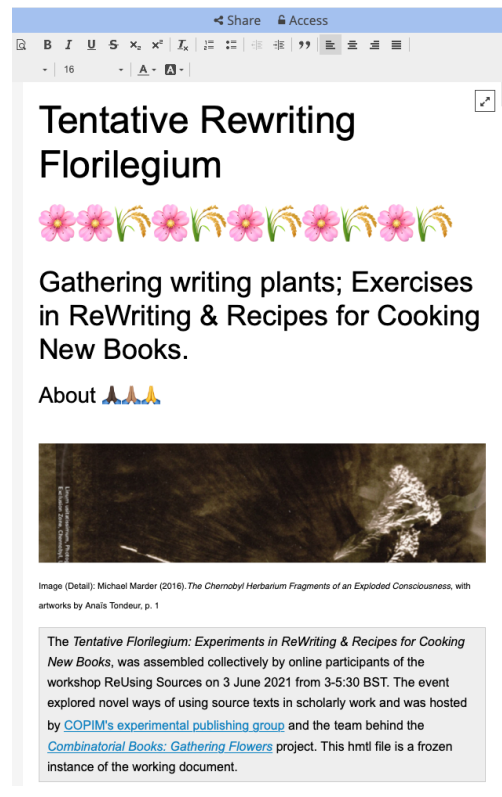

During the workshop, we cowrote a Tentative Rewriting Florilegium on Cryptpad. Below, we publish a frozen instance of the ongoing and open-ended experiment for you to share and enjoy as a link, and embedded:

Tentative Rewriting. Florilegium

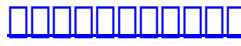
Gathering writing.plants; Exercises in ReWriting \& Recipes for Cooking New

Visit the web version of this article to view interactive content.

Tentative Rewriting_Florilegium: Gathering writing_plants; Exercises in ReWriting\& Recipes for Cooking_New Books. (on CryptPad) 
